\title{
Comparing pollen spectra from modified Tauber traps and moss samples: examples from a selection of woodlands across Europe
}

\author{
Heather S. Pardoe • Thomas Giesecke - Willem O. van der Knaap • \\ Helena Svitavská-Svobodová · Eliso V. Kvavadze · Sampson Panajiotidis • \\ Achilles Gerasimidis · Irena A. Pidek • Marcelina Zimny • Joanna Święta-Musznicka • \\ Małgorzata Latałowa $\cdot$ Agnieszka M. Noryśkiewicz $\cdot$ Elissaveta Bozilova • \\ Spassimir Tonkov $\cdot$ Mariana V. Filipova-Marinova $\cdot$ Jacqueline F. N. van Leeuwen • \\ Laimdota Kalninga
}

Received: 17 December 2009/ Accepted: 5 May 2010

(C) The Author(s) 2010. This article is published with open access at Springerlink.com

\begin{abstract}
This paper compares pollen spectra derived from modified Tauber traps and moss samples from a selection of woodland types from Bulgaria, the Czech Republic, Georgia, Greece, Poland, Switzerland and Wales. The study examines the representation of individual taxa in the two sampling media and aims to ascertain the duration
\end{abstract}

Communicated by F. Bittmann.

Electronic supplementary material The online version of this article (doi:10.1007/s00334-010-0258-y) contains supplementary material, which is available to authorized users.

\section{H. S. Pardoe ( $\square)$}

Department of Biodiversity and Systematic Biology, National Museum Wales, Cathays Park, Cardiff CF10 3NP, UK

e-mail: Heather.Pardoe@museumwales.ac.uk

T. Giesecke

Department of Palynology and Climate Dynamics, University of Göttingen, Albrecht-von-Haller-Institute for Plant Sciences, Untere Karspüle 2, 37073 Göttingen, Germany

W. O. van der Knaap · J. F. N. van Leeuwen Institute of Plant Sciences and Oeschger Centre for Climate Change Research, University of Bern, Altenbergrain 21, 3013 Bern, Switzerland

H. Svitavská-Svobodová

Institute of Botany, Academy of Sciences of the Czech Republic, Castle 252-43, Průhonice, Czech Republic

E. V. Kvavadze

National Museum of Georgia, Davitashvili Institute

of Paleobiology, 4 Niagvris St, 0108 Tbilisi, Georgia

S. Panajiotidis · A. Gerasimidis

Laboratory of Forest Botany-Geobotany, Faculty of Forestry and Natural Environment, Aristotle University of Thessaloniki, PO Box: 270, 54124 Thessaloniki, Greece of pollen deposition captured by a moss. The latter aim was pursued through the calculation of dissimilarity indexes to assess how many years of pollen deposited in a pollen trap yield percentage values that are most similar to those obtained from the moss. The results are broadly scattered; the majority of moss samples being most similar to several years of pollen deposition in the adjacent trap. For a selection of samples, a comparison of the pollen accumulation rate in pollen traps with the pollen concentration in the moss per unit surface indicates that the entrapment and/ or preservation of individual pollen types in the moss differ from that in the pollen trap. A comparison of the proportion of different taxa in the moss with the pollen spectrum of

\section{A. Pidek}

Institute of Earth Sciences, University of Maria Curie-

Skłodowska, al. Kraśnicka 2 c/d, 20-718 Lublin, Poland

M. Zimny · J. Święta-Musznicka · M. Latałowa

Department of Plant Ecology, Laboratory of Palaeoecology and Archaeobotany, University of Gdańsk, al. Legionow 9, 80-441 Gdańsk, Poland

A. M. Noryśkiewicz

Institute of Archaeology, Nicolaus Copernicus University in Toruń, Szosa Bydgoska 44/48, 87-100 Toruń, Poland

\section{E. Bozilova $\cdot$ S. Tonkov}

Faculty of Biology, Department of Botany, Laboratory of Palynology, Sofia University of St. Kliment Ohridski, 8 Dragan Tzankov blvd, 1164 Sofia, Bulgaria

M. V. Filipova-Marinova

Museum of Natural History, 41 Maria Louisa blvd, 9000 Varna, Bulgaria

L. Kalnina

Faculty of Geography and Earth Sciences, University of Latvia, 19 Rainis Blvd, Riga 1586, Latvia 
2 years of pollen deposition in the trap also revealed large differences. There is a tendency for bisaccate grains such as Pinus and Picea to have a higher representation in moss than in traps but there is considerable regional variation. The results indicate that pollen proportions from moss samples often represent the pollen deposition of one area over several years. However, bisaccate pollen grains tend to be over-represented in moss samples compared to both pollen traps and, potentially, lake sediments.

Keywords Moss sample - Modified Tauber trap · Surface pollen deposition - Collecting efficiency . Representation of tree taxa $\cdot$ Dissimilarity measures

\section{Introduction}

The collection of surface pollen in moss samples for calibration datasets or modern analogues is now a wellestablished technique (see for example Hicks 1977; Hjelle 1998; Caseldine 1989; Pardoe 1996, 2001, 2006; Tonkov et al. 2001). Moss samples are also used extensively in studies of pollen productivity and dispersal (Räsänen et al. 2004), such as those published by Broström et al. (2004, 2008). However, few studies have examined the underlying assumptions of the technique or compared the assemblages obtained from moss samples with assemblages from other surface sampling media (Boyd 1986; Cundill 1991; Vermoere et al. 2000; Tonkov et al. 2001; Räsänen et al. 2004; Cundill et al. 2006). Of particular interest is the length of time reflected by the pollen assemblage retrieved from moss. According to Cundill (1991) there is considerable disagreement in the literature over the age of the moss material collected for different studies. For example, Crowder and Cuddy (1973) suggest that their moss samples have accumulated pollen and spores over a period of between 5 and 15 years, while Bradshaw (1981) suggests that his moss samples contain about 5 years of accumulation and Caseldine (1981) surmises that there is at least 2 years of pollen and spore deposition in his mosses. Räsänen et al. (2004) suggest that in Hailuoto (Finland) pollen is retained in the moss for less than 2 years.

The Tauber trap is a widely used technique to collect modern pollen and is the main technique employed by the Pollen Monitoring Programme (PMP) (Hicks et al. 1996, 1999, 2001). Pollen-trap data can be used for the same aims as those from moss samples, but also for other aims that require absolute pollen values (pollen grains per surface unit per time unit), rather than the relative values (percentages of pollen) from moss. However, pollen-trap data can also be presented as percentages, in which case they are equivalent to pollen data from moss samples. One point, however, has still to be clarified: are pollen-trap data, calculated as percentages, fully equivalent to moss sample data? In other words, do traps capture the different pollen types in the same proportions as moss samples? This is an important question; although it has been raised before it has received only little attention (see for example Hicks and Hyvärinen 1986; Cundill 1991; Räsänen et al. 2004).

This paper focuses on the two questions raised above. How many years of pollen are represented in our moss samples? Are the proportions between pollen types in moss samples the same as in pollen traps at the same location? We study this in a range of woodland types from across Europe and the Caucasus, from where we have pollen results from adjacent pollen traps and moss samples.

We also consider the factors that influence pollen deposition and retention in moss samples and traps. Modern pollen assemblages, obtained both from moss samples and pollen traps, are important as modern analogues for past vegetation, in pollen/climate calibration sets, and for estimating pollen productivity. Our results have therefore implications for the interpretation of Holocene vegetation.

This paper presents results from the Pollen Monitoring Programme (PMP), which was launched in 1996 (Hicks et al. 1996, 1999). A broad network of sites has been established, mainly across Europe and in the Caucasus. At these sites pollen traps are placed and collected annually after the main flowering season. The record of trap data spans over 10 years now, providing a good basis for comparison with other sampling media (in Switzerland, pollen trapping began in 1992). Moss samples have been collected adjacent to most pollen traps in order to compare the pollen spectra from the two sampling media.

\section{Methods}

Field methods

\section{Pollen collection in traps}

The results from 81 field sites in seven countries (Great Britain, Poland, Czech Republic, Switzerland, Bulgaria, Greece and Georgia) are evaluated in this study. Details of the location and dominant vegetation at the individual sites are summarised in Fig. 1 and ESM (additional online resources) Table S1.

Pollen samples have been collected annually in modified Tauber traps (see Hicks et al. 1996, 1999 for a full description of the trap). Generally the researchers have followed the standard methods described in the guidelines (Hicks et al. 1996, 1999). The trap has a circular opening on top, usually $5 \mathrm{~cm}$ in diameter, through which the airborne pollen can freely enter (Table 1). Formaldehyde, glycerol and thymol are placed in the trap to inhibit the 
Fig. 1 Map of sampling sites; 1 Capel Curig, Wales, Great Britain; 2 Aletschwald, Riederhorn and Zermatt, Switzerland; 3 Šumava Mountains, Czech Republic; 4 Kashubian Lakeland, Poland; 5 Tuchola Forest Yew Reserve, Poland; 6 Roztocze National Park, Poland; 7 Black Sea coast, Bulgaria; 8 Rila Mountains,

Bulgaria; 9 Pieria Mountains,

Greece; 10 Lagodekhi

Reservation, Georgia

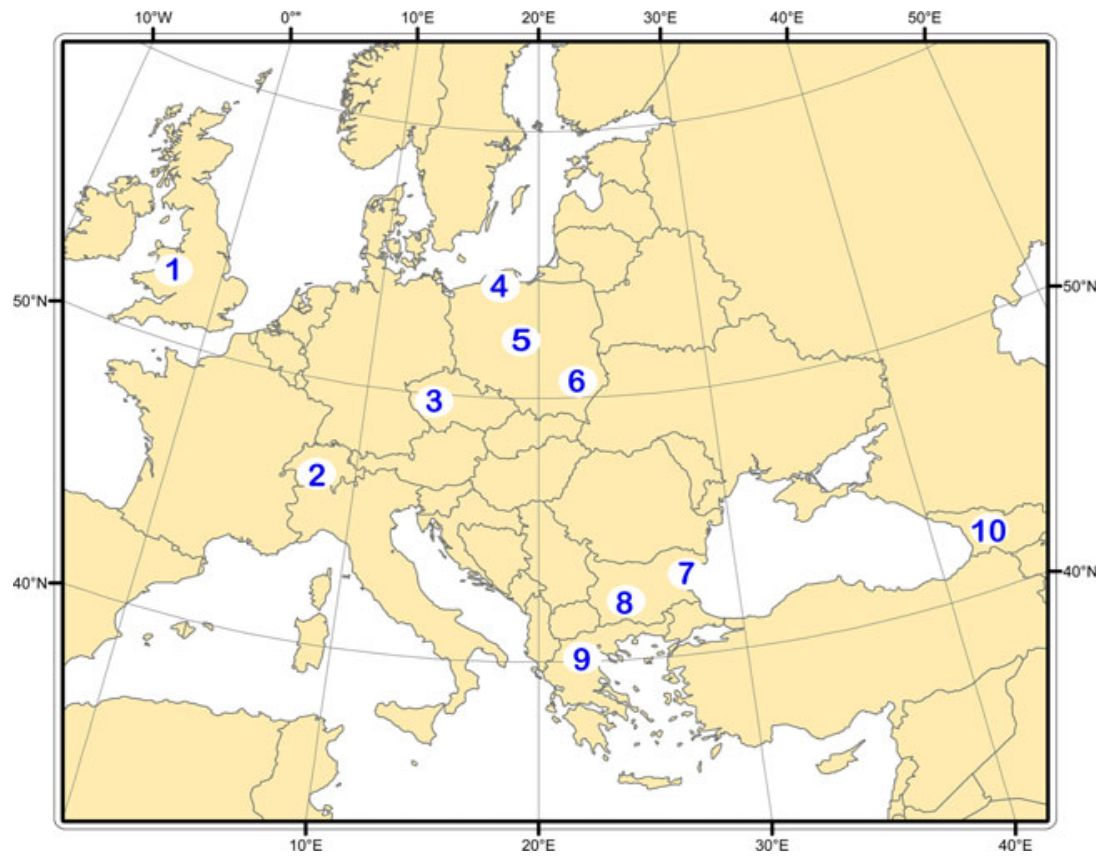

Table 1 Summary of moss sample collecting methods and laboratory methods

\begin{tabular}{lllll}
\hline Study area & $\begin{array}{l}\text { Number of sub-samples } \\
\text { of moss }\end{array}$ & $\begin{array}{l}\text { Diameter of moss sample } \\
\text { at ground level }(\mathrm{cm})\end{array}$ & $\begin{array}{l}\text { Basal sections } \\
\text { of moss }\end{array}$ & $\begin{array}{l}\text { Diameter of Tauber trap } \\
\text { opening }(\mathrm{cm})\end{array}$ \\
\hline Great Britain: Wales & 20 & Unknown & Included & 5 \\
Switzerland $^{\text {a }}$ & $\geq 10$ & Unknown & Not included & 5 \\
Czech Republic & $7-10$ & Unknown & Not included & 3.5 \\
Poland: Kashubian Lakeland & 1 & 9 & Not included & 7 \\
Poland: Tuchola Forest, Wierzchlas & 1 & 5 & Not included & 4.1 (W1) 5 (W2, W3) \\
Poland: Roztocze National Park & 1 & 5 & Not included & 5 \\
Greece & 1 & 5 & Included & 5 \\
Bulgaria: Rila Mountains & 1 & 5 & Included & 5 \\
Bulgaria: Black Sea Coast & Several & Unknown & Included & 4.5 \\
Georgia & b & 5 & Not included & 5
\end{tabular}

${ }^{a}$ Occasionally litter collected instead of moss. Excess liquid in the trap samples was siphoned off in the laboratory

b Trap samples were centrifuged in heavy cadmium liquid prior to acetolysis

growth of mould and to prevent the decay of any animals inadvertently captured. The traps are buried so that the opening is just above the ground surface. The analysis was based on pollen trap and moss sample results from the same year (ESM Table S1) and also pollen trap results for several years prior to this (see analysis section).

\section{Pollen collection in moss samples}

In this paper we use the results of moss samples collected on one occasion at each site, although some contributors have collected moss samples on several occasions (ESM Table S1). A standard technique for the collection of moss samples has not been adopted. Researchers from Switzerland, Great Britain (Wales), Eastern Bulgaria and the Czech Republic have collected moss samples, from close to the traps, comprising up to 20 sub-samples, and/or litter when moss was scarce or absent. The remaining researchers have collected a single moss sample near each trap. In four localities (Western Bulgaria, Poland, Greece and Georgia) the area of moss sampled at the ground surface was determined by collecting the moss within a small tube of known diameter (Table 1). The moss samples were collected after the flowering season together with the pollen traps. The moss samples analysed are listed in ESM Table S1. The different collecting techniques are summarised in Table 1. 
Laboratory methods

Laboratory preparation of both the trap samples and the moss samples has been conducted in accordance with the Pollen Monitoring Programme Guidelines (Hicks et al. 1996, 1999). Water was removed from the trap samples, either by sieving the sample through filter paper or sieving cloth, or by centrifuging off excess water. The pollen was then extracted using standard laboratory techniques, namely heating in sodium hydroxide or potassium hydroxide, treatment with hydrofluoric acid when necessary and acetolysis.

The moss samples were boiled in $10 \%$ potassium hydroxide or sodium hydroxide, thoroughly shaken and sieved through a coarse sieve to remove the moss. The pollen, suspended in solution was extracted using the same techniques as for the trap samples. Any exceptions are listed in Table 1. Lycopodium tablets were added to the trap samples and to those moss samples whose surface area was measured (as described above) before sample preparation, permitting the calculation of pollen concentrations for each taxon (Stockmarr 1971).

\section{Data analysis}

Insects that have collected pollen from herbaceous species sometimes enter the pollen trap, which may lead to spurious results for these taxa. Therefore we restrict this analysis to pollen types from common, wind-pollinated trees and shrubs, which also form the sum for percentage calculations. The exclusion of herbs has the further advantage that small scale differences in vegetation cover between the position of the pollen trap and the moss sample will have little influence on the pollen proportions.

When using pollen percentage values it is difficult to assess how many years of pollen deposition are represented in a moss. We therefore approached the question by ascertaining the number of years of pollen deposition in a pollen trap which yield percentage values that are most similar to those obtained from the moss. Similarity was assessed by the Euclidean distance and the squared chord distance (SCD). These dissimilarity indices were calculated between the pollen percentages from the moss and the percentage values calculated over an increasing number of years of pollen deposition before the collection of the moss.

The Euclidean distance between two samples is strongly influenced by large differences between few or even single taxa, while the squared chord distance reduces this effect and gives more weight to the overall composition of the sample. Thus a small Euclidean distance will indicate a close fit between abundant pollen taxa, which often show large year-to-year fluctuations in pollen production. A small squared chord distance on the other hand will indicate a good similarity across all taxa in the sample and thus take account of the flowering variability of less abundant taxa.

The percentages of individual pollen taxa in trap samples were calculated as follows. Pollen accumulation rates (PAR) were calculated for individual years. These values were successively added and pollen percentages were calculated from the sum of two, three and more years. As pollen traps and moss were collected at the end of the flowering season, 1 year of pollen trapping represents the flowering season before moss collection.

The surface area of the moss sample was determined and exotic markers added prior to sample preparation in four study areas (Roztocze National Park, Poland; Tuchola Forest Yew Reserve, Poland; Greece; Georgia). In these cases the pollen concentration of each taxon could be divided by the surface area and expressed as grains $\mathrm{cm}^{-2}$. These values could then be directly compared to successive annual deposition rates from the associated trap.

The different representation of individual pollen types in the moss sample versus the pollen trap were calculated and expressed as percentage of the larger value:

$\left(\mathrm{m}_{\mathrm{i}}-\mathrm{t}_{\mathrm{i}}\right) / \operatorname{MAX}\left(\mathrm{m}_{\mathrm{i}}, \mathrm{t}_{\mathrm{i}}\right) \times 100$

The difference is calculated between the percentages of taxon $\mathrm{i}$ in the moss sample $\left(\mathrm{m}_{\mathrm{i}}\right)$ and the percentage in the associated trap $\left(t_{i}\right)$. The difference is divided by the larger of the two percentages values $\left(\mathrm{m}_{\mathrm{i}}, \mathrm{t}_{\mathrm{i}}\right)$ to obtain values within +100 to $-100 \%$. The percentages for the pollen trap are based on the pollen accumulation over 2 years as early results indicated that 2 year averages may be more representative.

The two approaches used to gain information on the temporal representation of pollen accumulation in moss samples are based on the assumption that the efficiency of pollen entrapment is the same for the trap and the moss. In order to evaluate this assumption, we have, therefore, to assume that the number of years of pollen deposition represented by the moss sample is known. These assumptions have to be made in order to facilitate any comparisons, although probably neither of them is true in all cases. However, this problem should be borne in mind when evaluating the results.

In this manuscript we use the concept of trapping efficiency to describe the differences between the capture of pollen in the moss versus the pollen trap. Tauber (1974) calculated the trapping efficiency of his trap design as the amount of pollen collected in the trap versus that impacted on a vertical cylinder in a wind channel. In Tauber's experiment the impacting pollen on the surface of the cylinder is a measure of the flux of grains passing over the trap, so that the efficiency could be expressed as the 
fraction that had been caught in the trap. In this study it is not possible to assess the absolute amount of pollen that could have been deposited during the year.

\section{Results and interpretation}

Similarity changes when more years are considered

Results of the dissimilarity calculations are presented in ESM Table S2, with the smallest numbers marked in red, representing the highest similarity. In many cases, the values for Euclidean distance and SCD decrease rapidly at first and level off after a few consecutive years. At the break of slope values often reach a local minimum (marked blue in ESM Table S2) and decrease only slightly thereafter (Fig. 2a). The example from the long time series from Switzerland illustrates the most frequent case that a local minimum in dissimilarity is obtained within a time window of few years only (Fig. 2a), while the absolute minimum is often found towards the end of the pollen trap series. In many of the shorter pollen trap series it is therefore not possible to know if what we see is a local or an absolute minimum. For this reason we focused on the first minimum in all datasets. In more than $90 \%$ of all cases the two dissimilarity indexes agree, showing a local or absolute minimum for the same number of years. A high similarity between the two pollen collecting media was reached in about $50 \%$ of all cases with 2 years of accumulated pollentrapping results. About $20 \%$ of the moss samples showed a high or the highest similarity with trap data from the same year, prior to moss collection (Fig. 2b). The remaining moss samples, about $30 \%$, showed at least a local minimum over 3-5 years.

When considering the different methods of obtaining the moss sample (ESM Table S2), it is interesting to note that in situations where the basal part of the moss was also collected, local or absolute minima for dissimilarity indexes are generally only obtained after 2 or more consecutive years of pollen trapping. However, few observations on moss collection are available, so that this result might have come about by chance. On average low SCDs are obtained from regions where the moss sample consisted of several sub-samples and somewhat higher SCDs where single moss samples were collected near each trap, but this tendency is weak and not significant. In fact the lowest SCD was calculated between a trap and a single moss sample.

\section{Regional observations}

As this dataset was compiled from different individual research projects from diverse regions, there are some regional differences due to site peculiarities such as the vegetation structure or type of moss sampled. The size of the dataset does not allow the presentation of all of these, often interesting, local stories that can be glimpsed from the results presented in ESM Table S2. Furthermore, Fig. 3 allows a visual comparison between the pollen proportions in the moss sample and those found in an amalgamation of pollen trap data collected during the year of moss collection and the previous year.

In Roztocze National Park (Poland), a defined surface area of moss was sampled. Here concentration can be divided by surface area to produce a value $\left(\right.$ grains $\mathrm{cm}^{-2}$ ) that is comparable to the pollen deposition from pollen traps (grains $\mathrm{cm}^{-2}$ year $^{-1}$ ) without the information on the time over which the accumulation of pollen occurred. A comparison with pollen accumulation rates from the associated pollen traps can thus provide an indication of the length of pollen deposition represented in the moss sample for individual taxa.

The difference between the pollen concentration in the moss and that in the trap for the year of sampling is
Fig. 2 Change in dissimilarity values between the moss sample and accumulated trapping results from trap A4 (a) and trap R5 (b), Switzerland. The $X$ axis represents the length of the time window of pollen-trap data, in which 1 represents the year of moss-sample collection. Blue diamonds = Euclidean distance; red dots = squared chord distance (SCD)
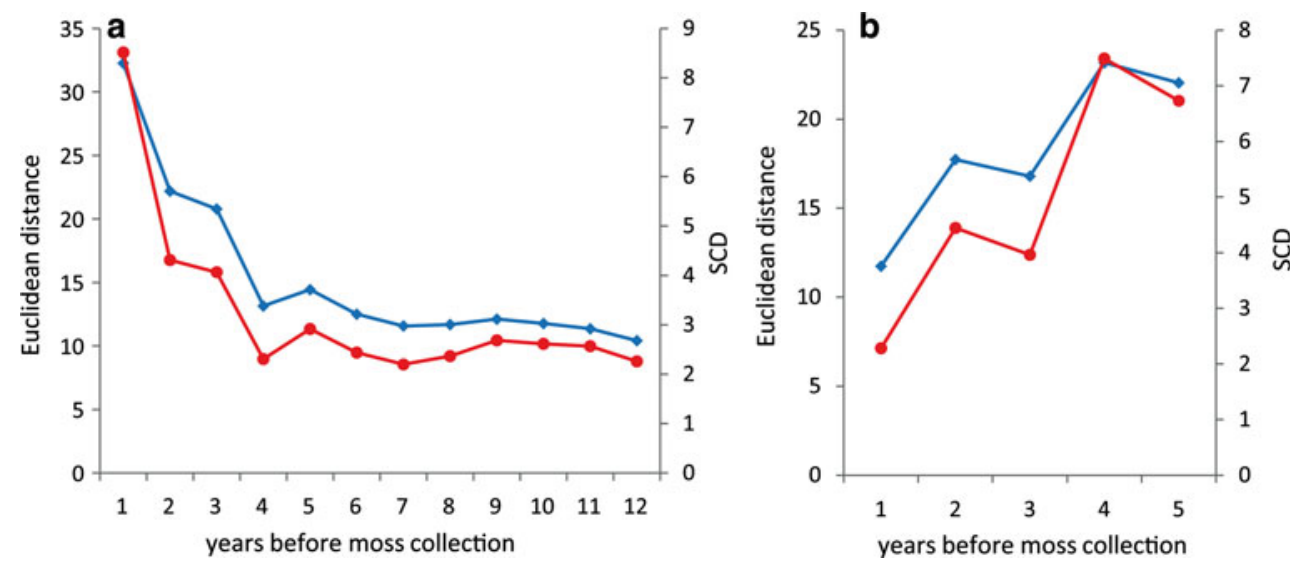


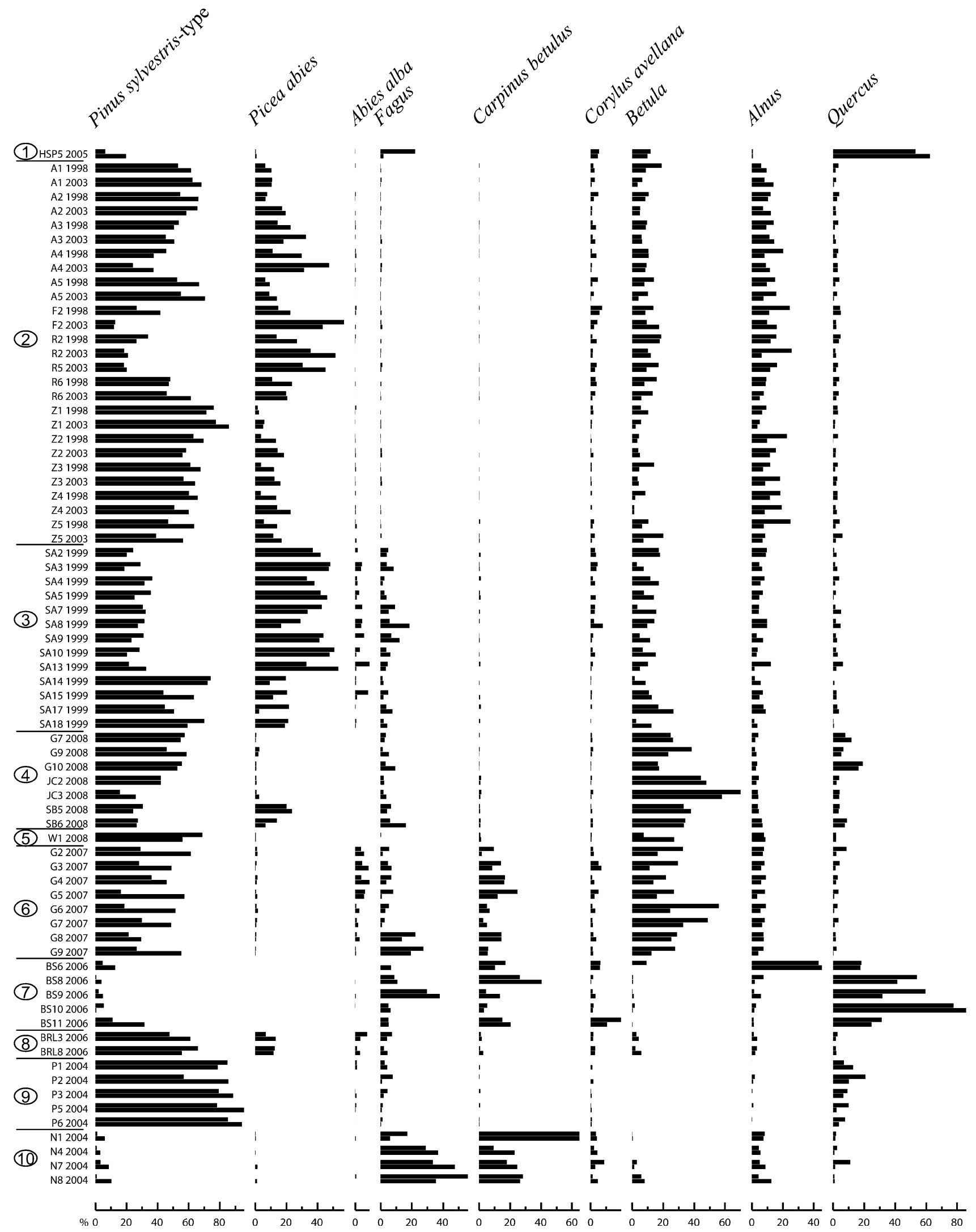

Fig. 3 Comparison of the pollen proportions for the major pollen types in the trap (upper bar) and the moss sample (lower bar) for a 2 year period of deposition in the trap. Study areas are numbered as in Fig. 1 
Fig. 4 Difference between the pollen deposition in the moss sample (grains $\mathrm{cm}^{-2}$ ) and PAR in the pollen trap (grains $\mathrm{cm}^{-2}$ year $^{-1}$ ) for the year of sample collection for sampling pairs from Roztocze National Park (Poland)

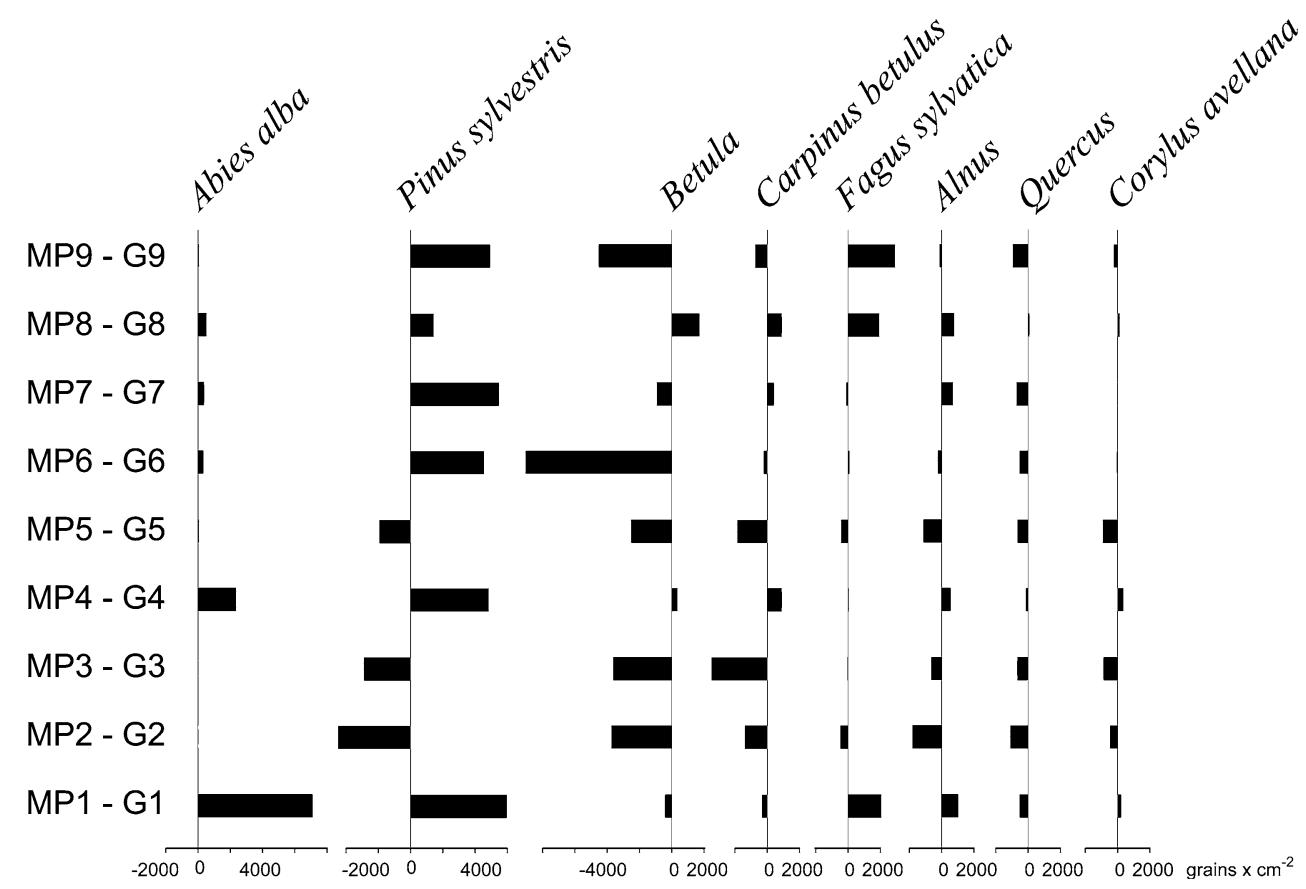

illustrated in Fig. 4. This shows that there is a large variability between the different taxa with respect to the values in the moss sample representing one or more years of pollen deposition. Only in the moss sample beside trap P8 do all taxa exceed the pollen deposition estimated from the trap. There was more Abies pollen in seven out of the nine moss samples compared to the trap and more Pinus in six moss samples compared to the corresponding trap for the year of collection. However, half of the samples with more Pinus pollen showed less Betula pollen than was deposited in the associated pollen traps. Moss samples that contained less Pinus pollen per surface area compared to the pollen trap, also show a local minimum in the dissimilarity for the year of sample collection. Sample pairs where most of the taxa have more pollen per surface area compared to the pollen trap of that year show lower dissimilarity values compared to the other pairs. Even though the moss sample MP8 does not contain much more pollen per surface area than deposited in the year of sampling in the pollen trap, the dissimilarity indices are further reduced if values of up to 4 years of pollen accumulation in the trap are considered.

Samples from the Pieria Mountains (Greece) are dominated by Pinus (57-95\% pollen) and Quercus (2-20\%) (Fig. 3). The strong dominance of Pinus hampers a trap/ moss comparison in terms of pollen percentages. Thus the availability of data on concentration per unit area from the moss samples offers important insights. The amount of Pinus and Quercus pollen per surface moss sample is higher than in the pollen trap for the year of sampling, apart from the pair for P1, which has the lowest dissimilarity indices. In most cases dissimilarity indexes are slightly higher for the 2-year trap values than for 1-year values, and a local minimum is usually reached for 3-year trap values (ESM Table S2). The moss sample for P1 is exceptional as it has a lower Pinus pollen deposition than the pollen trap for the year of sampling but the values of Quercus and Fagus exceed that of 2 years of pollen trapping. With the exception of this sample pair, Pinus pollen deposition in the moss sample accounts for up to 5 years of pollen accumulation in the associated traps while Quercus accounts for up to 4 years.

In Switzerland, where pollen is monitored in four different study regions (van der Knaap et al. 2010), moss samples were collected in 2 years (1998 and 2003). This allows a comparison of the moss-sample/trap dissimilarity results between the two moss collections (Fig. 3, ESM Table S2). When the collections are compared, only 4 out of 11 pairs show a similar pattern in the change of dissimilarity indexes. However, the greatest differences occur between sampling sites.

In the Rila Mountains (Bulgaria), moss samples were collected every year with the collection of the pollen traps. For trap BRL3 moss samples are available for 5 consecutive years, and Euclidean distance and SCD are relatively low for all collection pairs of all these years using 1 year pollen trap data. The comparison of the pair collected in 2006 with up to 5 years of pollen accumulation in the trap shows that the dissimilarity indexes decrease slightly if more years are considered and the dissimilarity values are only somewhat lower compared to the annual pairs of moss and trap. 
The data collected from the Kashubian Lakeland and Gdańsk (Poland) yield similar dissimilarity patterns for all moss/trap collection pairs but one, and the lowest dissimilarity is reached for the 2-year trap window. Trap and moss sample JC2/JC2-M show the lowest SCD score for the entire dataset for 2 years of pollen trapping. A high resemblance in dissimilarity patterns between moss/trap pairs is also seen in the data from the Šmava Mountains (Czech Republic), and also here the lowest values are reached with the 2-year time window.

Due to the loss of the pollen trap in individual years, in Tuchola Forest Yew Reserve (Poland) and Capel Curig (Wales, Great Britain) only one moss/trap pair is available for comparison. In Tuchola Forest Yew Reserve, the lowest dissimilarity is reached with the 1-year trap data, and the dissimilarity indexes rise strongly if more years are included. In Capel Curig the situation is opposite and the lowest value is reached with the 5-year trap data (no longer time windows available). The trap but not the moss has a high Fagus value for the year of pollen collection, which causes a high dissimilarity, whereas the consecutive earlier years have low Fagus pollen in the trap.

Data from three different forest types from the Black Sea Coast (Bulgaria) were available for this comparison. However, traps and moss samples from one of the forests (BS08/ BS08S, BS09/BS09S and BS10/BS10S) are as different from each other as they are from the other two forest types.

Samples from the Lagodekhi Reservation (Georgia) come from an altitudinal transect with changing forest types. Here more similarities can be observed between the paired samples, e.g. the pollen composition in the moss samples MPN4 and MPN7 is most similar to the pollen trap content of the year of sampling.

Representation of bisaccate pollen in moss versus pollen traps

Figure 5 summarizes the difference in percentages between the sum of bisaccate grains (Picea, Pinus and Abies) in the moss sample and the 2-year pollen value in the trap. The maximum difference is $41 \%$, the minimum $-17 \%$, and the median $7 \%$. In $67 \%$ of all paired samples, the proportion of bisaccate pollen was larger in the moss sample than in the trap.

The proportion of bisaccate pollen differs markedly among study regions. For example, among the datasets with five or more paired moss/trap samples, Roztocze National Park (Poland) has a higher proportion of bisaccate pollen in all moss samples, whereas in Šumava (Czech Republic) only two out of thirteen pairs have a higher proportion of bisaccate pollen in traps. The difference in representation of bisaccate pollen between the moss and the trap has a strong influence on the dissimilarity indexes.
The difference in proportion of bisaccate pollen between the moss sample and the trap is often large and involves only a few taxa. Therefore the discrepancy is well captured by the Euclidean distance (Fig. 6). The datasets from Roztocze National Park, Kashubian Lakeland, Gdańsk (Poland) and Pieria Mountains (Greece) with a high proportion of Pinus pollen even show regression coefficients above 0.9 with Euclidean distance as the dependent variable. However, the removal of bisaccate pollen types from the pollen sum does not always result in a reduction of the dissimilarity indexes and where the proportions of bisaccate pollen are high they may stabilize the relative proportions between the other pollen types. Removing bisaccate grains from the analysis does not often produce a different pattern of dissimilarity indexes over successive years.

Pollen representation in moss compared to traps

Comparison of the representation of bisaccate pollen in the moss sample and the trap has shown that the representation



Fig. 5 Difference in the proportion of bisaccate pollen grains in pairs of moss and trap samples. For the pollen traps percentages were calculated from two consecutive years of pollen deposition prior to collection of the moss

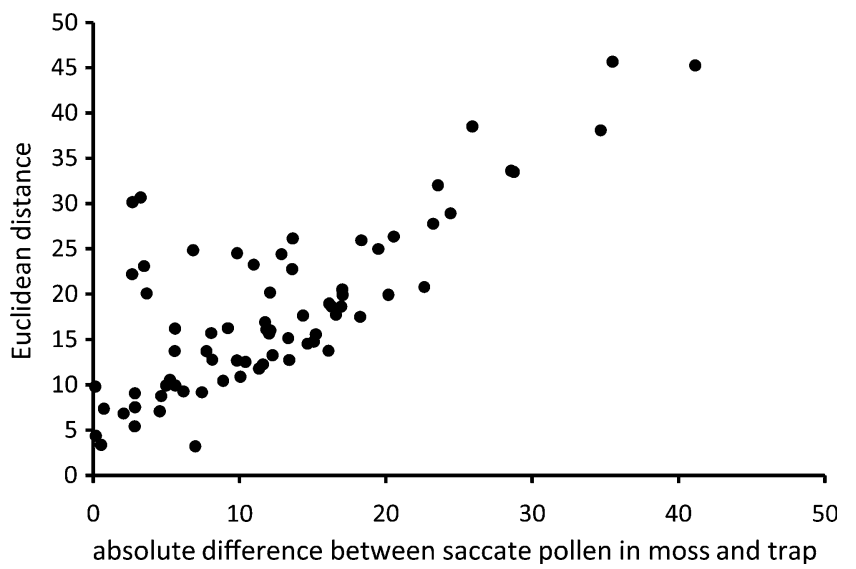

Fig. 6 Scatterplot showing the influence of the difference in bisaccate pollen on the Euclidean distance measure between the percentage pollen composition in the moss sample and 2 years pollen accumulation in the pollen trap 
of different pollen types is not always consistent. Figure 7 illustrates the percentage differences of the individual taxa in the moss sample and the pollen trap. This representation shows whether there is a tendency for different pollen types to have higher values in the moss sample or in the trap.

A higher percentage of Pinus and Picea pollen occurred in most cases in the moss sample, while higher percentages of Quercus were obtained from pollen traps. Also Betula and Alnus were generally found to have higher percentage values in the traps. Fagus, Carpinus and Corylus assume an intermediate position with a tendency for higher percentages to occur in the moss sample. Although the bisaccate pollen type of Abies generally attained higher percentages in the moss sample, it was found with much higher percentage values in a number of pollen traps, which is indicated by the frequent high negative values. Thus the spread of values is largest for Abies and smallest for Pinus pollen.

\section{Discussion}

The fundamental question that we are trying to answer is whether moss samples and pollen traps yield similar pollen spectra from the same vegetation. The results show that the pollen deposition in pollen traps can differ considerably from that in a moss adjacent to the trap. The main factors responsible for this discrepancy emerging from this study are:

(i) The time during which pollen accumulates in the moss may vary between a few months and several years.

(ii) The moss may retain some pollen types more efficiently than others and differential preservation may alter this further.

\section{Pollen deposition time}

One way to approach the question of how many years of pollen deposition is represented by a moss sample is to estimate the pollen concentration and compare it to the results from the nearby pollen trap. This makes it necessary to obtain a moss sample with a defined surface area and assume a constant growth over this surface. Four datasets were available in this study containing this type of information and of these, two yielded particularly valuable results. The estimates from Roztocze National Park (Poland) indicate that the moss samples accumulated pollen over a period ranging from less than 1 year to about 2 years (Fig. 4). The Greek data, on the other hand, indicate that some moss samples accumulated pollen over 4-5 years. Räsänen et al. (2004) applied the same method and suggested that the moss samples analysed from Hailuoto (Finland) represented more than one but less than 2 years of pollen deposition in the pollen trap. Lisitsyna (personal communication 2007) suggested that a comparable period of between 2 and 3 years was found in Fennoscandia.

Pollen monitoring shows a high inter-annual variability in pollen deposition. Many tree taxa, such as Fagus, show long periods of low pollen production and occasional years when pollen production is high (Pidek et al. 2010). Tonkov et al. (2001) note that in good flowering years high percentages of Picea and Fagus are recorded in the traps but not in the moss samples, whilst in an average year moss samples usually show higher percentages for these two taxa. This led them to conclude that the moss samples cannot represent a single season.

In the same way the calculation of similarity indices can indicate how many years of pollen deposition are represented by a moss sample. If a moss sample contains more than 1 year of pollen deposition, its pollen proportion should be more similar to percentages calculated over several years of pollen accumulation in the trap. Thus the large majority of moss samples in this analysis would have accumulated pollen for more than a single year. In Greece, for example, the results indicate that pollen in the moss samples compares best with pollen collected in traps over a period of 3 years on average. However, for a number of paired samples the difference between the moss sample and the trap did not improve significantly or even worsened when several years of pollen accumulation were averaged. Consequently, these moss samples are likely to represent only a single year of pollen deposition or less.

\section{Differential retention of pollen types in the moss}

The two approaches that were used to estimate the duration of pollen deposition in a moss sample assume that the moss sample has the same trapping efficiency as the pollen trap. However, our results show that in many cases this assumption is not valid. The samples from Roztocze National Park (Poland) showed that, for some taxa, the pollen accumulated in the moss was equivalent to more than 1 year's pollen deposition in the trap, while for other taxa the same moss sample contained less than a year of pollen deposition. The representation of bisaccate pollen (Picea, Pinus, Abies) in particular differed widely between the moss sample and the pollen trap (Fig. 6). Over-representation of Pinus pollen especially in moss samples was also suggested in earlier studies (Caramiello et al. 1991; Vermoere et al. 2000). However, other pollen types also showed different tendencies of higher or lower proportions in the pollen trap versus the moss sample with strong regional differences (Fig. 7).

Some of these differences may be explained by the particular surface of the moss, which retains pollen types of varying size, form and surface roughness differentially. Joosten and de Klerk (2007) noted that some air-borne 

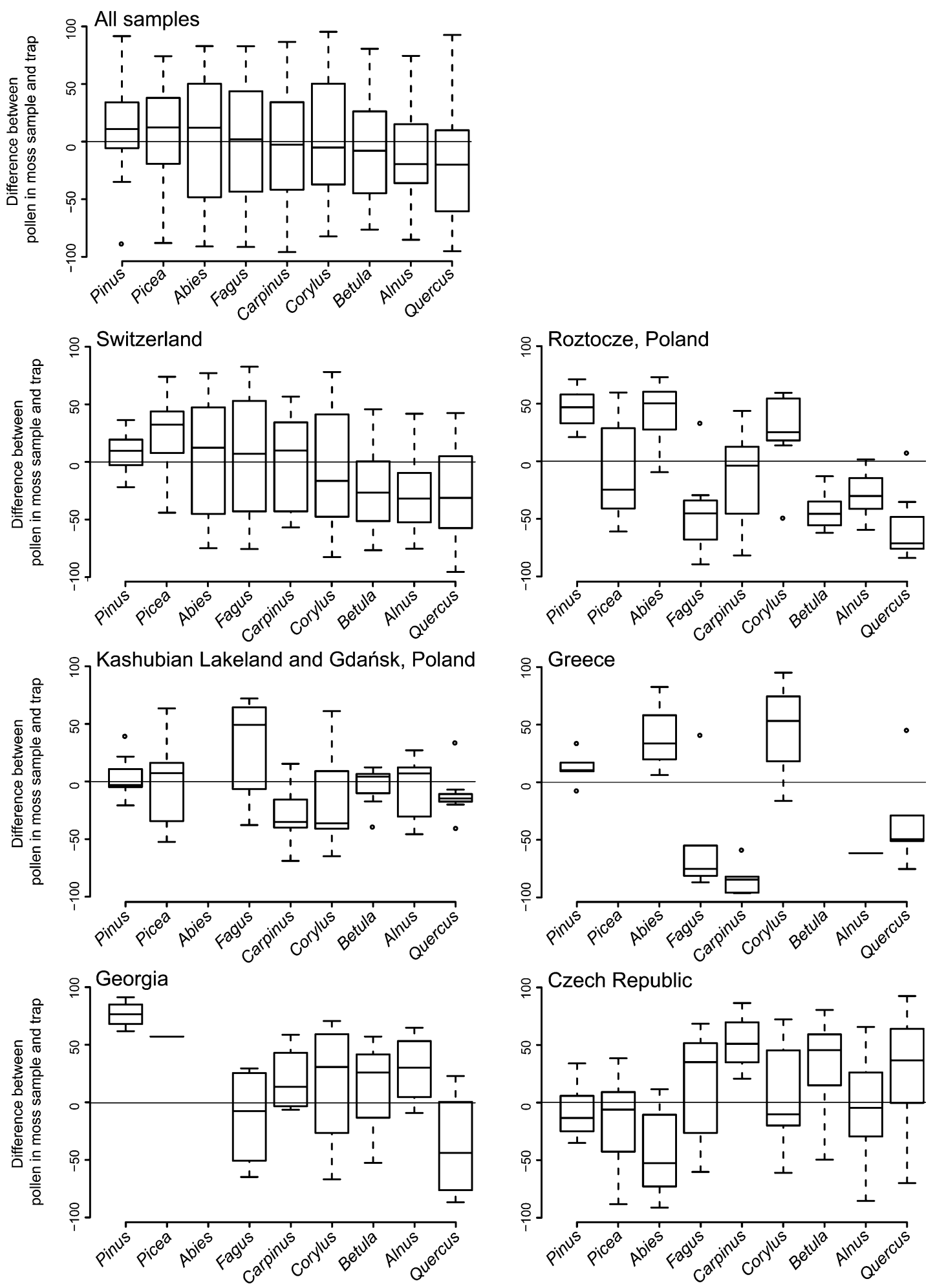

Fig. 7 Box plots showing the percentage differences of the relative abundance of individual pollen types in the moss versus the pollen trap. Higher proportions of a taxon in the moss sample are represented

pollen grains will adhere to the dense mat of Sphagnum capitula, whereas others will drift through the interstices into the underlying more open moss space (cf. Overbeck by positive values and higher percentages in the pollen trap by negative values. The graphs show the results for all samples as well as for regions for which at least 4 sample pairs were available

and Happach 1957; Overbeck 1975). Joosten and de Klerk (2007) found evidence of inter-annual mixing of pollen grains. Furthermore, they suggested that animals such as 
Collembola (springtails) could move pollen between layers of peat. Rowley and Rowley (1956) observed that the small and spheroidal Dodonaea pollen percolated downwards in the interstices of the living Sphagnum, while the large and bisaccate Pinus pollen remained trapped at the surface. Clymo and Mackay (1987), on the other hand, reported insignificant differences in motion distances of injected Corylus and Cedrus pollen and Lycopodium spores. They attributed the discrepancy between their results and those of Rowley and Rowley (1956) to different abilities of pollen types to penetrate the Sphagnum capitula.

Tauber (1974) has shown that wind speed and the taxon specific fall speed of pollen had an influence on the trapping efficiency of the pollen trap, with small grains being captured more efficiently than large grains at high wind speeds but less efficiently in calm conditions. The traps used in this study were not equipped with the aerodynamic collar designed by Tauber (1974) and thus turbulence would have affected pollen deposition more than in the original design. However, the pollen traps were sunk into the ground which would reduce air velocity near the opening. Site characteristics such as position relative to trees and shrubs would further influence local air velocities. This could explain some local differences in pollen deposition.

Fægri and Iversen (1989) studied the combined effects of wind speed and surface-roughness by showing the contrast between settling of pollen, which is most effective in calm weather and for which a trap is well suited, and deposition in moving air, which is a scavenging process whereby pollen adheres to rough surfaces across and through which it is blown. Already Tauber (1977) had shown that pollen scavenging by a Salix shrub was effective. Also Bennett and Hicks (2005) recognised that there are systematic differences between pollen samples from peats and pollen traps.

\section{Differences in results between study regions}

The remarkable differences in differential pollen representations between study regions shown in Fig. 6 strongly suggest that at least some of the factors responsible differ between regions. There are several potential explanations. One possibility is that the average number of years represented by pollen in the moss samples differs between the study areas, whereas the calculations for Fig. 6 are standardized for 2 years of pollen trapping. A 2-year period was chosen since this is close to the overall average number of years of trapped pollen that best corresponds to pollen in the moss samples. Where the pollen from the pollen trap and moss sample has been deposited over unequal periods, the consequence may be that only one of the two registers a peak year for some pollen types.
Another possibility is that the average wind speed during the pollination season at the pollen collection sites differs between the study regions. This is quite feasible, since in some regions most traps are placed predominantly in open, windy situations and in other regions predominantly in relatively sheltered forest. Yet another possibility is that the average pollen-interception properties of the moss collected could differ between the regions. Boyd (1986), for example, has shown that mosses of different growth forms vary in their pollen entrapment efficiency. He suggested that mosses with tall turfs, erect branches, or diverging branches show least differential loss of pollen. The predominant growth-form of moss probably differed between the different study regions, which might thus contribute to regional differences in the representation of pollen types in the trap versus the moss sample. We have insufficient information to evaluate these potential explanations, but the results indicate that factors such as microclimate and habitat at pollen-collection sites and the mode and material of moss sampling are important.

\section{Implications for Holocene studies}

The results of this study show that the representation of different pollen taxa differs between trapping media and this has implications for many palynological studies. In large datasets or between-site comparisons moss samples are rarely combined with pollen traps, but with samples from the sediment-water interface of lakes. Giesecke and Fontana (2008) have compared pollen deposited in modified Tauber traps with pollen deposited in lakes and found that bisaccate Pinus pollen especially was lost on the way through the water column. Thus while bisaccate pollen has the tendency to be better represented in moss samples compared to pollen traps, even lower proportions may be achieved in samples from lake sediments. Donner et al. (1978) produced a pollen diagram from a lake and an adjacent bog, with about $20 \%$ less Pinus pollen in the diagram from the lake. The authors attributed this to the effect of local Pinus trees growing on the bog surface, but it may also be affected by some of the processes discussed above.

Extensive surface-pollen datasets used to elucidate the pollen-vegetation relationship or to infer transfer functions often contain a mixture of moss samples and surface-mud samples from lakes. Here the effect of a differential deposition of pollen taxa in different media would have greatest influence. While mixing samples from different pollen-collecting media in one dataset may increase the noise-to-signal ratio, comparing studies based on a dataset from lakes and one from moss samples may reveal systematic offsets. 
One such comparison, where the differential trapping of pollen taxa could influence the results, is that of pollen productivity estimates, where some were based on lake surface samples and others on moss samples (Broström et al. 2008). Recently pollen traps have also been used to estimate pollen productivity (Sjögren et al. 2008, 2010; Sugita et al. 2009; Filipova-Marinova et al. 2010). The application of some of these pollen productivity estimates to pollen diagrams from lakes and bogs may be biased.

Methods of collecting moss samples

Opinion is divided on the best method of collecting moss samples, the number of sub-samples to collect, whether to include the dead basal moss parts in the sample, collecting just one growth form of moss or using a bulk sample of several growth forms. For example, the best modern analogue of a fossil sample might be a single moss sample, since fossil samples from a peat core are also from a single location. However, previous studies such as Pardoe (1996) have shown a high degree of local variability in pollen assemblages collected in moss samples over a small area. It might, therefore, be preferable to combine several subsamples since this will be more representative of the local vegetation.

There are many potential problems associated with the growth-form and density of the moss. Where there is a choice of moss taxa, we should perhaps collect one genus for the sake of consistency. Sphagnum is an obvious candidate since it is relatively widely distributed, relatively easily identified, often has a dense growth-form, and is the taxon of which many peat sections are composed. However, both growth rates and form vary in response to local conditions, and Sphagnum is not available near many traps.

This study did not show clear influences of the moss collection method on the results. However, trends in the data indicate that the collection of the dead basal part of the moss will increase the number of years included in the sample. Also the combination of several moss sub-samples in one location into one combined sample may be advantageous. However, the results from a single sample may be just as good, but this may depend on local conditions.

\section{Conclusions}

The results show that the pollen deposition in moss samples compares best, in most cases, to an average pollen deposition in the pollen trap over at least 2 years and often considerably longer periods. Thus most moss samples collected for this comparison would yield a representative sample reflecting average conditions, while as many as $20 \%$ of the moss samples may capture a single year of pollen deposition and thus do not represent the average conditions.

There is a tendency for bisaccate pollen (Pinus, Picea, Abies) to attain higher percentages in the moss samples compared to the pollen traps. There is a large scatter in the data and pronounced regional differences are present. These differences could influence the results of studies on the pollen/vegetation relationship where moss samples and/ or pollen traps are utilized and may also affect the representation in lake sediments.

Acknowledgements We dedicate this paper to Sheila Hicks on the occasion of her retirement. We are grateful to her for both her vision in establishing the Pollen Monitoring Programme and her enthusiasm and support as the PMP has developed. The Czech part of pollen monitoring research was supported financially by the Academy of Sciences of the Czech Republic AV0Z60050516. Part of this work has been supported financially under research project No N304 092 $32 / 3590$ by the Polish Ministry of Science and Higher Education (years 2007-2010). This research is part of the Pollen Monitoring Programme PMP (INQUA working group; http://pmp.oulu.fi/) and contributes to the European Union project Millennium-European climate of the last millennium (SUSTDEV-2004-3.1.4.1).

Open Access This article is distributed under the terms of the Creative Commons Attribution Noncommercial License which permits any noncommercial use, distribution, and reproduction in any medium, provided the original author(s) and source are credited.

\section{References}

Bennett KD, Hicks S (2005) Numerical analysis of surface and fossil pollen spectra from northern Fennoscandia. J Biogeogr 32:407423

Boyd WE (1986) The role of mosses in modern pollen analysis: the influence of moss morphology on pollen entrapment. Pollen Spores 28:243-256

Bradshaw RHW (1981) Modern pollen-representation factors for woods in south-east England. J Ecol 69:45-70

Broström A, Sugita S, Gaillard M-J (2004) Pollen productivity estimates for the reconstruction of past vegetation cover in the cultural landscape of southern Sweden. Holocene 14:371-384

Broström A, Nielsen A, Gaillard M-J, Hjelle K, Mazier F, Binney H, Bunting J, Fyfe R, Meltsov V, Poska A, Räsänen S, Soepboer W, von Stedingk H, Suutari H, Sugita S (2008) Pollen productivity estimates of key European plant taxa for quantitative reconstruction of past vegetation: a review. Veget Hist Archaeobot 17:461-478

Caramiello R, Siniscalco C, Piervittori R (1991) The relationship between vegetation and pollen deposition in soil and in biological traps. Grana 30:291-300

Caseldine CJ (1981) Surface pollen studies across Bankhead Moss, Fife, Scotland. J Biogeogr 8:7-25

Caseldine CJ (1989) Pollen assemblage-plant community relationships on the Storbreen glacier foreland, Jotunheimen Mountains, southern Norway. New Phytol 111:105-118

Clymo RS, Mackay D (1987) Upwash and downwash of pollen and spores in the unsaturated surface layer of Sphagnum-dominated peat. New Phytol 105:175-183 
Crowder AA, Cuddy DG (1973) Pollen in a small river basin: Wilton Creek Ontario. In: Birks HJB, West RG (eds) Quaternary plant ecology. Blackwell, Oxford, pp 61-78

Cundill PR (1991) Comparisons of moss polster and pollen trap data: a pilot study. Grana 30:301-308

Cundill P, Austin WEN, Davies SE (2006) Modern pollen from the catchment and surficial sediments of a Scottish sea loch (fjord). Grana 45:230-238

Donner JJ, Alhonen P, Eronen M, Jungner H, Vuorela I (1978) Biostratigraphy and radiocarbon dating of the Holocene lake sediments of Työtjärvi and the peats in the adjoining bog Varrassuo west of Lahti in southern Finland. Annales Botanici Fennici 15:258-280

Fægri K, Iversen J (1989) Text book of pollen analysis, 4th edn. Wiley, New York

Filipova-Marinova MV, Kvavadze EV, Connor SE, Sjögren P (2010) Estimating absolute pollen productivity for some European Tertiary-relict taxa. Veget Hist Archaeobot 19. doi:10.1007/ s00334-010-0257-z

Gerasimidis A, Panajiotidis S, Hicks S, Athanasiadis N (2006) An eight-year record of pollen deposition in the Pieria mountains (N. Greece) and its significance for interpreting fossil pollen assemblages. Rev Palaeobot Palynol 141:231-243

Giesecke T, Fontana SL (2008) Revisiting pollen accumulation rates from Swedish lake sediments. Holocene 18:293-305

Hicks S (1977) Modern pollen rain in Finish Lapland investigated by analysis of surface moss polsters. New Phytol 78:713-734

Hicks S, Hyvärinen V-P (1986) Sampling modern pollen deposition by means of "Tauber traps": some considerations. Pollen Spores 28:219-242

Hicks S, Ammann B, Latałowa M, Pardoe H, Tinsley H (1996) European pollen monitoring programme: project description and guidelines. Oulu University Press, Oulu

Hicks S, Tinsley H, Pardoe H, Cundill P (1999) European pollen monitoring programme: supplement to the guidelines. Oulu University Press, Oulu

Hicks S, Tinsley H, Huusko A, Jensen C, Hättestrand M, Gerasimides A, Kvavadze E (2001) Some comments on spatial variation in arboreal pollen deposition: first records from the Pollen Monitoring Programme (PMP). Rev Palaeobot Palynol 117:183-194

Hjelle KL (1998) Herb pollen representation in surface moss samples from mown meadows and pastures in western Norway. Veget Hist Archaeobot 7:79-96

Joosten H, de Klerk P (2007) In search of finiteness: the limits of fineresolution palynology of Sphagnum peat. Holocene 17:1,023-1,031

Kvavadze E (1999) The first results of the Pollen Monitoring Programme in the Caucasus Mountains. (Georgia). Acta Palaeobot 39:171-177

Kvavadze E (2001) Annual modern pollen deposition in the foothills of the Lagodekhi Reservation (Caucasus, East Georgia) related to vegetation and climate. Acta Palaeobot 41:355-364

Overbeck F (1975) Botanisch-geologische Moorkunde. Wacholtz, Neumünster

Overbeck F, Happach H (1957) Über das Wachstum und den Wasserhaushalt einiger Hochmoorsphagnen. Flora 144:335-402

Pardoe HS (1996) Micro-scale patterns of modern pollen deposition within three alpine plant communities. New Phytol 132:327-341
Pardoe HS (2001) The representation of taxa in surface pollen spectra on alpine and sub-alpine glacier forelands in southern Norway. Rev Palaeobot Palynol 117:63-78

Pardoe HS (2006) Surface pollen deposition on glacier forelands in southern Norway I: local patterns of representation and source area at Storbreen, Jotunheimen. Holocene 16:1,149-1,161

Pidek IA (2004) Preliminary results of pollen trapping in the region of the Roztocze National Park (SE Poland). Annales UMCS, sec. B, 59, Lublin:143-159

Pidek IA, Svitavská-Svobodová H, van der Knaap WO, Noryśkiewicz AM, Filbrandt-Czaja A, Noryśkiewicz B, Latałowa M, Zimny M, Święta-Musznicka J, Bozilova E, Tonkov S, FilipovaMarinova M, Poska A, Giesecke T, Gikov A (2010) Variation in annual pollen accumulation rates of Fagus along a N-S transect in Europe based on pollen traps. Veget Hist Archaeobot 19. doi:10.1007/s00334-010-0248-0

Räsänen S, Hicks S, Odgaard BV (2004) Pollen deposition in mosses and a modified 'Tauber trap' from Hailuoto, Finland: what exactly does the moss record? Rev Palaeobot Palynol 129:103116

Rowley JR, Rowley J (1956) Vertical migration of spherical and aspherical pollen in a Sphagnum bog. Proc Minn Acad Sci 29-30

Sjögren P, van der Knaap WO, Huusko A, van Leeuwen JFN (2008) Pollen productivity, dispersal, and correction factors for major tree taxa in the Swiss Alps based on pollen-trap results. Rev Palaeobot Palynol 152:200-210

Sjögren P, Connor SE, van der Knaap WO (2010) The development of composite dispersal functions for estimating absolute pollen productivity in the Swiss Alps. Veget Hist Archaeobot 19. doi: 10.1007/s00334-010-0247-1

Stockmarr J (1971) Tablets with spores in absolute pollen analysis. Pollen Spores 13:615-621

Sugita S, Hicks S, Sormunen H (2009) Absolute pollen productivity and pollen-vegetation relationships in northern Finland. J Quat Sci, doi:10.1002/jqs.1349

Tauber H (1974) A static non-overload pollen collector. New Phytol 73:359-369

Tauber H (1977) Investigations of aerial pollen transport in a forested area. Dansk Botanisk Arkiv 32:1-121

Tonkov S, Hicks S, Bozilova E, Atanassova J (2001) Pollen monitoring in the Central Rila Mts., Southwestern Bulgaria: case studies from pollen traps and surface samples for the period 1994-1999. Rev Palaeobot Palynol 117:167-182

Van der Knaap WO, van Leeuwen JFN, Ammann B (2001) Seven years of annual pollen influx at the forest limit in the Swiss Alps studied by pollen traps: relations to vegetation and climate. Rev Palaeobot Palynol 117:31-52

Van der Knaap WO, van Leeuwen JFN, Svitavská-Svobodová H, Pidek IA, Kvavadze E, Chichinadze M, Giesecke T, Kaszewski BM, Oberli F, Kalnina L, Pardoe HS, Tinner W, Ammann B (2010) Annual pollen traps reveal the complexity of climatic control on pollen productivity in Europe and the Caucasus. Veget Hist Archaeobot 19. doi:10.1007/s00334-010-0250-6

Vermoere M, Vanhecke L, Walelkens M, Smets E (2000) A comparison between modern pollen spectra of moss cushions and Cundill pollen traps. Grana 39:146-158 